\title{
Audit in the therapy professions: some constraints on progress
}

\author{
Sarah Robinson
}

\begin{abstract}
Aims-To ascertain views about constraints on the progress of audit experienced by members of four of the therapy professions: physiotherapy, occupational therapy, speech and language therapy, and clinical psychology.

Methods-Interviews in six health service sites with a history of audit in these professions. 62 interviews were held with members of the four professions and 60 with other personnel with relevant involvement. Five main themes emerged as the constraints on progress: resources; expertise; relations between groups; organisational structures; and overall planning of audit activities.
\end{abstract}

Results-Concerns about resources focused on lack of time, insufficient finance, and lack of access to appropriate systems of information technology. Insufficient expertise was identified as a major constraint on progress. Guidance on designing instruments for collection of data was the main concern, but help with writing proposals, specifying and keeping to objectives, analysing data, and writing reports was also required. Although sources of guidance were sometimes available, more commonly this was not the case. Several aspects of relations between groups were reported as constraining the progress of audit. These included support and commitment, choice of audit topics, conflicts between staff, willingness to participate and change practice, and concerns about confidentiality. Organisational structures which constrained audit included weak links between heads of professional services and managers of provider units, the inhibiting effect of change, the weakening of professional coherence when therapists were split across directorates, and the ethos of regarding audit findings as business secrets. Lack of an overall plan for audit meant that while some resources were available, others equally necessary for successful completion of projects were not.

Conclusion-Members of four of the therapy professions identified a wide range of constraints on the progress of audit. If their commitment to audit is to be maintained these constraints require resolution. It is suggested that such resolution not only requires additional resources and greater availability of expert advice, but also that these are directed towards the particular needs of the four professions. Moreover, a forum is required within which all those with a stake in therapy audit can acknowledge and resolve the different agendas which they may have in the enterprise.

(Quality in Health Care 1996;5:206-214)

Keywords: therapy professions, audit

\section{Introduction}

This paper is concerned with the development of audit in some of the healthcare professions in the United Kingdom. A considerable amount of time, effort, and indeed money has been invested in medical audit. Much less money, however, has been invested in the development of nursing audit, and even less in audit in the therapy professions discussed in this paper. Quality assurance activities in the therapy professions began in the mid-1980s when each of the professional bodies produced national standards for a wide range of aspects of care. ${ }^{1}$ Subsequently, individual practitioners initiated audit of many of these standards. ${ }^{23}$

\section{Audit}

- Medical audit is a systematic critical analysis of the quality of medical care, including the procedures used for diagnoses and treatment, the use of resources, and the resulting outcome and quality of life for the patient

- Medical audit was initially motivated by professional concerns and promoted by individual enthusiasts - managerial involvement increased alongside moves to make the service more commercially oriented

-Audit in the nursing and therapy professions was similarly motivated by professional concerns and increasingly became the subject of managerial involvement

-Although uniprofessional activities continue in medicine, nursing, and the therapy professions, much more emphasis is now placed on multiprofessional and clinical audit - the approach advocated in the 1990s by the Department of Health

The development of audit in the therapy professions as a whole was then given considerable impetus in 1991 by the Department of Health's decision to fund a 
three year programme to "enable the widespread take up of audit in the nursing and therapy professions". ${ }^{4}$ Although therapists, like medical staff, originally conceived of audit as a uniprofessional activity, they became increasingly involved in multiprofessional activities after the promotion of clinical audit by the Department of Health. ${ }^{5}$

The volume of research which now exists on participation by medical staff in audit activities has identified a wide range of constraints which may hinder progress. These constraints include lack of time and guidance, ${ }^{6}$ authority to implement findings, ${ }^{7}$ and concerns about the extent to which findings are regarded as confidential. ${ }^{8}$ Comparable research for the therapy professions is scarce; it is however, important to know what constraints may be experienced by therapists if their quality assurance activities are to be sustained. Consequently, investigation of constraints was one of the main aims of a project funded by the Department of Health, commissioned to investigate audit activities in occupational therapy, physiotherapy, speech and language therapy, and clinical psychology, and to make recommendations for future practice. This focus on constraints was also a response to an earlier investigation of audit in these professions which had concluded that more facilities and support for audit activities should be provided for clinicians. ${ }^{9}$

\section{Methods}

The research design was a qualitative study with semistructured interviews held with health service staff in six sites. Interviews were chosen rather than questionnaires to collect data, as little previous research existed to guide the formulation of a questionnaire, and discussions with key informants indicated a complex situation not readily amenable to fixed choice questions. Concentrating the interviews at a few sites, rather than interviewing a sample of staff spread nationwide, meant that audit could be considered in the context in which it occurred.

SELECTION OF SITES

Six sites were selected; each was a unit of organisation in the health service (usually a trust) in which one or more of the four professions were actively engaged in audit. The selection was purposive to ensure a diversity of those criteria most likely to affect the nature of audit: client group, clinical setting, organisational structures, and regional policies. The process of selecting the six sites entailed searching audit databases and published work and consultations with the project's advisory group, which was comprised primarily of members of the four professions.

SELECTION OF INTERVIEWEES

At each site our aim was to interview all members of the four therapy professions involved in audit activities, as well as other "stake holders" in these endeavours. The stake holders included medical and nursing staff involved in multiprofessional audit, managers of provider units, purchasers, and quality advisors and coordinators. A letter requesting agreement to be interviewed was sent to each person identified. This stressed the voluntary nature of participation, together with assurances of confidentiality and anonymity. Nearly all those approached agreed to participate.

APPROACH TO INTERVIEWING

Six main topics (box) were explored with all participants using a semistructured interview schedule. Identification of items within the topic areas and associated probes drew on discussions with key informants and on the professional and research literature on audit. The schedules were piloted in a seventh site before the main field work to clarify terminology, assess relevance of items included, identify omissions, and determine acceptability of topic sequencing and overall duration of interview.

Topics explored in the interviews:

- Audit activities in the therapy

professions, in progress at local and regional level

- Initiation and management of audit

- Own involvement in audit

- Resources and support for undertaking audit

- The impact of audit on the delivery of care and on professional development

- Future directions for the development of audit

The interviews were recorded on audiotape to: (a) have a verbatim record; (b) avoid breaks in the conversation to write notes; and (c) enable the researcher to be free to detect cues - such as unease or hesitancy that indicated the need to probe a subject further. Respondents were asked for their views about audit in their profession generally, as well as drawing on their own experience of participation in audit activities. The tapes were transcribed by the interviewer to provide a full account for analysis. Reasons for not tape recording included refusal of the interviewee and the occasional technical mishap. Immediately after such an event, the interviewer wrote up a comprehensive account from notes taken during the interview to ensure as great a degree of comparability as possible with the transcriptions of tape recorded interviews. Most interviews lasted about an hour. Many expressed surprise that they had talked for so long; as one interviewee said:

"I would never have thought I had so much to say about audit”.

\section{ANALYSIS}

The aim of the analysis was to identify key issues in the development of audit, and the range of experience and views in relation to each; it was not to produce precise measurement of the kind " 20 people said this, whereas 25 said that...". The content of the transcripts was analysed with the framework approach described by Ritchie and Spencer. ${ }^{10}$ Familiarity with content of the transcripts was gained by repeated reading, enabling the main 
themes and subthemes within the data set as a whole to be identified. Some of these themes reflected the topics in the interview schedules, whereas others related to new issues raised by interviewees. Each interview was then plotted on a matrix by summarising the responses relating to each of these themes.

\section{Results}

A total of 122 people were interviewed. Sixty two were members of the therapy professions - heads of professional service as well as staff at each of the clinical grades. The other 60 interviewees were the other stake holders in audit. Taken together, the six sites in which these interviewees worked represented a diversity of client groups (elderly people, those with mental health problems, learning disabilities, physical disabilities, and rehabilitation needs); and of settings (hospitals of varying size, community units, and services).

Over 100 uniprofessional and multiprofessional audit activities at varying stages of completion were identified. The following examples illustrate the diversity of aspects of care being investigated: improving the quality of record keeping; achieving equity of access to physiotherapy services; reviewing case notes to identify antecedents of incidents of self harm; improving information provided for stroke patients and their carers; assessing outcomes of a rehabilitation programme for patients with head injuries; developing a system to measure quality of life outcomes for long term mental health clients; ascertaining the relation between waiting time after referral for osteoarthritis of the knee and subsequent outcome; and designing new treatment protocols and new staff training packages for the care of patients with dysphagia.

The therapists who were interviewed regarded audit as responsible for some positive impacts on the delivery of care, and on the morale and careers of individual members of the four professions. (These findings have already been reported in full by Kogan et al. ${ }^{11}$ ) At the same time, however, they identified many constraints to the progress of audit and these are reported here. Five main themes of constraints emerged from the analysis of the transcripts: resources; expertise and advice; relations between groups; organisational structures; and the extent to which an overall plan for audit existed. The main focus of results presented here is the constraints experienced by therapists; however, the extent to which the other groups of interviewees endorsed the therapists' views or offered alternative perspectives is also included.

\section{RESOURCES}

Time

Almost all interviewees identified lack of time as the main constraint on progress; finding convenient meeting times for all those involved as well as time to undertake the work entailed. Meetings were especially problematic when projects involved several health professions or were based in the community.
Constraints on the progress of audit

(1) LACK OF RESOURCES

- Time to undertake audit work and to meet with colleagues involved in audit

- Funding for equipment and secretarial support

- Appropriate systems of information technology

(2) LACK OF EXPERTISE OR ACCESS TO ADVICE IN

- Writing proposals

- Specifying and keeping to objectives

- Designing instruments

- Analysing data

- Writing reports

(3) RELATIONS BETWEEN GROUPS

- Lack of commitment by managers to use findings of audit projects

- Restrictions on choice of audit topic

- Conflict between staff

- Reluctance to participate and change practice

- Concerns about confidentiality

(4) ORGANISATIONAL STRUCTURES

- Weak organisational links between professionals and managers of provider units

- Change in organisational structure

- Loss of professional confidence when groups split across directorates

- Insecurity of audit facilitators' posts

- Restrictions on sharing audit findings in a climate of competition for contracts

(5) LACK OF AN OVERALL PLAN FOR AUDIT

"It's more difficult to get everyone together geographically, plus many community workers are part timers and it's hard to find a time when everyone can get together. It shouldn't put us off, but it does."

Few interviewees had been given a time allowance for audit activities and so these were undertaken in clinical time or in their own time. Audit being held in clinical time led to concerns about compromising care to spend time on audit. A junior member of staff said:

"I haven't got the time to do it and I feel I have to give patient care priority over this audit project. It's harder to give time to things that are long term."

And a head of service commented:

"It's hard for staff to take on extra work, especially when there is a waiting list. They have to weigh it up - do I spend time on audit or on patient care and they choose the latter - there's no contest as far as they are concerned."

Long intervals between audit meetings and lack of time for the work itself, meant that project schedules slipped; this had become disheartening, particularly after an enthusiastic and committed start.

The other interviewees endorsed the views expressed by the therapists - that lack of time was the main constraint on audit activities. The 
quality coordinators thought that the clinical commitments of therapists were too heavy for them to undertake audit. Some of the more senior managers took the view that the problem was their responsibility.

"If you're going to do it, you should do it properly, and allow people time to do it properly, particularly the heads of service."

Various suggestions to improve the situation were made by therapists: increasing overall staff numbers, appointing audit assistants to collect and collate data, and establishing bank systems to provide cover for those involved. Suggested patterns of work included allocating a proportion of everyone's working week to audit, and allocating several consecutive days to those involved in large scale projects as this led to better progress, especially at the outset.

\section{Funding}

Some projects were carried out within existing budgets whereas others had small sums allocated for specific items; some had received funding part way through, whereas others received funding of several thousand pounds from the outset. When funding was inadequate, clinical managers said they could "lose" costs such as photocopying, stationery, and secretarial help, in other budgets. However, when this was combined with the amount of personal, unpaid time spent on audit then, in the view of many, its true cost was not properly accounted.

Lack of finance for audit was not disputed by the other interviewees. The quality coordinators, in particular, saw this as a major constraint: firstly, there was little money available and it was not easy to obtain; secondly, once a project that was funded came to an end there was a loss of impetus to continue with audit activities.

\section{Information technology}

Although all the therapists acknowledged that information technology could contribute to the progress of audit, only a few had access to such systems. Several projects had been undertaken without word processing or computerised data capture facilities; all information was stored in handwritten records and analysed manually. As a head of service explained, this had often proved extremely time consuming.

"In many of our services, there is not an efficient system, many of us are still coping on manual systems. For the period of the project we kept manual records, but it took $26 \%$ of staff time, and was virtually unusable because data on one thing didn't match up with others."

Others had been asked to enter data for audit projects into systems that, in their view, were either not appropriate to the project's requirements or were difficult to use.

"This database is the background for the project, as well as being used for records generally. It's a new system, so there have been lots of hiccups and it's very slow to put things in. It's also a problem to get information out. When we kept manual records I could tell you at the end of every month how many patients, under which consultant, of which type we had treated and details of treatment. Now it's all in a computer which I can't access from here. The man in charge doesn't know what we want and what we want tends to evolve anyway."

Considerable emphasis was placed by therapy staff on consultation about the kinds of systems they needed, rather than presenting them with packages developed for other users. Moreover, they said that staff needed time and tuition to become competent with new systems.

Although members of the other groups were in agreement with the views about information technology expressed by the therapists, some of the managers said that they had encountered resistance when they had attempted to introduce a new system. One described the following reaction:

"I won't have anything to do with that, not at all. I want my own old word processor, nothing's going to get me away from that."

\section{EXPERTISE AND GUIDANCE}

Five aspects of undertaking audit projects were identified as needing expertise: writing proposals; specifying and keeping to objectives; designing instruments; analysing data; and writing reports. Sources of guidance specified by interviewees included colleagues with audit experience, holders of posts with a quality assurance remit, staff of specialist audit or research units, published work, and audit information networks. Some heads of professional services said that although courses on audit were available, their continuing education budget was limited, and staff chose to go on clinical courses rather than on audit courses when faced with a choice. Interviewees differed considerably in their experience of audit; a few had been involved for many years, others were just starting out on their first project. An indication of the lack of depth of audit experience, however, was provided by those who said that having completed or even just started one project, they were then seen as "experts" and asked to advise others.

"While we were doing the project, and finding out how to do it, suddenly our names were being given to loads of people, and we were being called in to advise them on their projects."

Without expert help in writing proposals, some interviewees doubted whether their bid for regional or provider unit money would have been successful. Difficulties had been experienced in specifying the focus of an audit project with sufficient precision to move forward into effective collection of data. Others thought that their group had lost its way by attempting to cover too many outcomes. A discussion with someone more experienced, usually an audit facilitator or coordinator, had often proved of great help in getting a project back on track. Clarity of objectives was seen as important, not only because it increased the 
likelihood that the project would be effective, but also because commitment was lost when purposes became unclear.

"I'm in favour of the project but I am not sure what are the next best steps with it and that's why I find it hard to find time for it."

The need for expert advice and guidance was expressed most often over designing instruments for collection of data - for example, a semistructured interview to obtain patients' views, or a questionnaire to staff on their training needs. Although examples were cited of help given for this, a much more common finding was that people wanted guidance, but did not know from whom or from where it might be obtained. Consequently, many instruments were designed without help and in ignorance of the range of existing instruments.

"At the moment, information about how to do it is patchy. We have had to make all our own contacts, we had to devise the questionnaire ourselves - there's been very little guidance".

"We've had very little advice on how to design forms and instruments. There probably is guidance, but it's not readily accessible."

Many of those who had considerable experience of audit activities and of instrument design expressed concern about people's lack of awareness of issues of validity and reliability.

"My concern was ... almost the naivety as to how simple it is to undertake audit, and I felt people were going to waste an enormous amount of effort and time drawing up half baked, non-scientific research without realising how difficult it is to construct good simple audit to change things."

A common problem was one of getting bogged down with excessive data; timely advice about focusing the analysis had been the reason for successful completion of several projects. Writing up findings into an accessible form for dissemination was difficult for those approaching the task for the first time.

"Staff may be willing to collect the data, but we do need help to collate and interpret it." Again, experienced input at this stage was seen as essential if the effort of undertaking audit was not to be wasted.

Nursing staff were more likely than their medical colleagues to express a need for guidance with audit activities. Concern about the validity of results when therapists were inexperienced was expressed by some of the managers and quality coordinators with responsibility to initiate change. As one put it:

"We have considerable difficulty in interpreting results."

And another talking about quality of questionnaires:

"Some are very well thought out, but there is some absolutely dire stuff - if work is to be used then it has to be done with objectivity."

RELATIONS BETWEEN GROUPS

Several aspects of relations within and between professions and between professionals and managers of provider units were reported as affecting the progress of audit: these included evidence of commitment, choice of audit topics, personal conflict, willingness to participate and change practice, and concerns about confidentiality.

\section{Commitment from managers}

Several heads of service said that although, in their view, professional staff were unanimously committed to the principles of audit, this was not always matched by support and commitment from managers. Instances were cited of findings from audit projects that had not been used, or even considered, particularly those concerned with delivery of care over long periods (for example, for clients with continuing mental health problems). This was a disincentive to further participation for those already stretched to capacity with clinical commitments.

"Junior staff who have joined audit activities become dispirited if it's not clear that the work is being used properly."

The view that lack of interest by managers acted as a disincentive to further participation in audit, also emerged from interviews with medical and nursing staff, purchasers, and quality coordinators. One quality coordinator expressed her views thus:

"...there is a desperate need for more support from senior managerial staff and acknowledgment for the work that is being done, rather than the occasional pat on the shoulder."

Managers themselves, however, offered two different reasons for the lack of action on findings from audit projects. Several managers said that in their view audit data were not collected systematically and so they found it difficult to interpret results and decide on a course of action. Secondly, some of the most senior managers interviewed, including a chief executive, observed that the success of trusts is judged to a disproportionate extent on the success of high profile medical work, and that no systematic consideration is given to audit reports from those professions with a much lower profile. Other managers stressed that they did act on findings, and always acknowledged receipt of audit reports and thanked the staff involved.

\section{Choice of topic}

The fieldwork provided many instances of aspects of care that had been of sufficient concern to motivate members of one or more of the four professions to undertake an audit project. An increasing managerial input into the choice of topics for audit projects was, however, identified as a constraint on attempts to audit the more complex aspects of care. Managers emphasised cost efficiency issues and topics that readily lent themselves to measurement. An often occurring example was the number of people seen within a given period. Many of those interviewed, however, 
thought that audit should be focusing on the quality of the encounter, not on its duration, and that the duration was an inappropriate use of staff time.

"My staff had to spend time on how long each patient waited - the paper work was enormous. It was pointless because we already had a system in which no one waited more that half an hour - so I said, "Can we just record exceptions?" - but they didn't like this. Much of the paperwork is meaningless and it takes up staff time."

Many of those with long experience of audit thought that whereas the original motivation had been to improve the quality of care, the managerial agenda was moving to one of cutting costs. Although not disputing that delivering high quality care as efficiently as possible should be the aim of the service, concern was expressed that quality was accorded a lower priority than hitherto. Not surprisingly, perhaps, the managers themselves did not describe the purpose of audit as one of reducing costs; they emphasised improving services and using resources effectively.

\section{Conflict between staff}

Most commonly interviewees described good staff relations which were conducive to the conduct of audit; instances of conflict were cited, however, which acted as a deterrent. One senior therapist who also had a remit as an audit coordinator described her experience of this.

"The two groups, community and acute, don't talk to each other. I've had one hell of a time getting them together to even talk about possible assessment tools that they might use...I've chaired their audit meetings continually to try to keep them on a happy footing. If you've got conflict within the team anyway, trying to get them to question each others' practice is very difficult..."

\section{Reluctance to participate and to change}

Some interviewees had experienced a reluctance by colleagues to participate in audit because of fear that ensuing recommendations might mean an unwelcome change in practice, or a reduction in autonomy, whereas others described a reluctance to accept changes which had been indicated.

"It's so stupid because it's very personalised as opposed to improving quality of care for patients ... it's sad because the service knows it has a problem, but just doesn't want to look at it."

"...You feel as if you are talking to a brick wall, and that all the findings in the world you produce aren't going to make them change their practice, and they don't realise that this is going to have an effect on the rest of the team."

Several of the more experienced interviewees stressed that audit projects, and their possible implications, should be discussed from the outset with all of those on whom findings might have an impact, as this was far more likely to achieve change than confronting people with a request for change out of the blue.

Managers also attributed reluctance of professionals to participate in audit to concerns about the changes which might result: attention was drawn, in particular, to a dislike of audit of the skill mix of teams. Other constraints on participation cited by managers included a dislike of audit that led to greater client empowerment and the view that audit was administrative, rather than professional work.

\section{Concerns about confidentiality}

Confidentiality of audit findings was a cause of concern for some interviewees. They said that improving patient care through audit had traditionally depended on colleagues learning from each other by being willing to share results, both good and bad. Willingness to participate was based on guarantees that proceedings were absolutely confidential to those involved. They thought that multiprofessional audit in particular was now making it more difficult to maintain confidentiality as several groups were involved; at some sites misunderstandings had already arisen as to who should share findings. Concern was also expressed about managers having access to audit findings as it was thought that they might use them to penalise staff in some way. Some therapists said that they now selected "safe" topics that they could not subsequently be "whipped by", although they thought that the end result of this strategy would be a failure to assess care given "warts and all".

None of the managers who were interviewed held the view that audit findings should remain confidential to the professionals involved; rather that the information should be available to all with an interest in, or responsibility for, the service in question. Some, however, did acknowledge that audit was threatening to professional staff.

"They think it is their capabilities that are being audited, rather than providing objective information on the services provided."

None the less, views expressed by other managers indicated that in some instances professional fears might not be without foundation; for example, one manager said:

"We will want to use audit as a form of supervision and accountability."

\section{ORGANISATIONAL STRUCTURES}

Organisational links between heads of professional services and managers of provider units affected implementation of audit. In sites with strong links, instances were cited of managers acting swiftly in response to audit findings. When links were weak, however, audit findings requiring managerial authority for implementation were said to "get stuck", as there was no route through which they could be channelled. Managers in these sites confirmed that they did not systematically 
consider reports on audit in the therapy professions; rather their attention was focused on medical audit.

Some sites were in the throes of considerable organisational change at the time of the fieldwork and managers expressed the view that this had prevented audit activities from getting underway. The nature of these changes meant that in some sites many interviewees were working in directorates other than the one in which their head of service was based. Some of the more senior therapy staff said that this led to loss of professional coherence, which in turn undermined confidence to undertake audit.

Various audit databases and advice networks had been established and provided information about methods used by others. This was particularly important for those relatively new to audit and lessened the likelihood of "reinventing the wheel". The quality assurance postholders responsible for these services, however, said that they were "too thinly spread" to meet all the demands on their time. Moreover, in some sites there was anxiety that their expertise might be lost altogether, as either the future of the audit post itself was uncertain, or the present incumbent had become dissatisfied with a series of short term contracts and was contemplating a move to a more secure job.

A view emerging from the interviews with therapists, although not from managers, was that the introduction of the quasi-internal market into health care and the separation of providers from purchasers had led to findings from audit projects being regarded as confidential to the trust. Such information was increasingly included in contract submissions and so should not be shared with others with whom the unit was potentially in competition.

"Some trusts are now banning sharing information about audit, because it's business secrets. This government has said you are in competition."

Some of the therapists thought that it was somewhat ironic that just as involvement in audit had become more widespread among members of the four professions, the ethos of competition between provider units might act as a deterrent to establishing a common body of knowledge and expertise.

AN OVERALL PLAN FOR AUDIT

In all sites the interview data indicated that although much audit activity was in progress, overall planning was lacking. Some projects, for example, had been well resourced with facilities and expertise, but had failed to make an impact due to poor links with appropriate levels of management. Other projects had failed to make progress despite initial commitment, because of time constraints of those involved. Some interviewees had been given a time allowance, but said that they failed to make progress because of lack of advice as to how to proceed at a particular stage. Some of the projects that had achieved an impact had succeeded due to the motivation and commit- ment of staff involved although they had been provided with little in the way of resources. Future commitment, however, was said to be dependent on this resource deficit being made good.

This lack of an overall plan was affirmed in the views expressed by the other groups of interviewees. Some of the senior managers expressed concern about the lack of coordination of audit activities across the trust and saw the development of an overall plan as one of their immediate priorities.

\section{Discussion}

This study of audit in four of the therapy professions indicated that although much activity was in progress, a wide range of constraints to progress had been experienced. These constraints (summarised in the box) deterred staff from undertaking audit, lessened the likelihood that projects would be completed, and restricted the choice of aspects of care likely to be selected for audit.

\section{The main constraints}

Availability of time was the main constraint to progress; other resource constraints identified were lack of finance for equipment and secretarial support, and inadequate or inappropriate information technology systems. Many interviewees did not have access to the kind of expertise that they thought was necessary, particularly in the design of instruments for collection of data and the interpretation of results. Concerns were expressed about the validity and reliability of results in the absence of appropriate advice, and at the loss of such advice that was available as some audit facilitators were seeking a move to more secure employment.

Aspects of relations between groups which served as a deterrent to participation in audit included loss of enthusiasm when audit findings were not used by managers, anxieties about the effects of recommendations on individual clinical practice, and fears that increasing loss of confidentiality meant that managers could use audit findings critical of practice to penalise staff. The choice of topics to be audited was restricted by increasing management emphasis on cost efficiency and by professionals avoiding audit of the more complex aspects of care. Other constraints to progress were attributed to changes in organisation of the health service. The splitting of therapists across directorates led to a loss of the professional confidence necessary to undertake audit, lack of formal connections between heads of service and general managers meant that audit findings were not always acted on, and the climate of competition between trusts for contracts was manifest in a growing reluctance to share audit findings.

Our sample was purposive rather than representative. The relevance of the results to those responsible for audit lies, therefore, not in the extent to which they can be generalised, but rather in the range of constraints identified, 
as these may be impeding the progress of audit in their own sites.

\section{Limitations of the study}

The constraints identified could all be described as external barriers - that is, they were respondents' perceptions of what prevented them from undertaking audit. It was a limitation of the study that internal cognitive barriers were not explored - namely, individual doubts about the value of audit Studies of doctors' views of audit suggest that such doubts do exist, ${ }^{12}$ and further research is needed to explore whether a comparable situation exists among members of the therapy professions. Although the present study showed that therapists thought that a lack of resources acted as a constraint to the progress of audit, precise measurement of additional resources was not obtained, and further research is required.

\section{Implications of the results}

It has been suggested that time for audit should not be a problem if it is integrated into the everyday working practices of health professionals. ${ }^{8}$ Although this may well be the case when staff are completing patient records in a format which makes them suitable for audit, it seems less feasible when, for example, they are designing instruments for collection of data or writing reports on findings. If clinical staff are to be allowed sufficient time to undertake audit and the level of client care is to remain the same, then additional resources are required. As suggested by respondents, these resources could take the form of extra staff, bank staff, and audit assistants; certainly audit assistants have been helpful to the progress of medical audit. ${ }^{1314}$

A much more comprehensive approach than that adopted to date is needed to clarify the role of information technology in audit in the therapy professions, and could build on a programme developed by Matchet and Rose for medical audit. ${ }^{15}$ This included a choice of software more appropriate to user's requirements, staff training programmes tailored to individual needs, and the appointment of technical support staff. It has to be recognised, however, that difficulties in choosing and installing appropriate information technology systems have long been a feature of medical ${ }^{15}$ and clinical audit, ${ }^{16}$ and it is unlikely to be different for audit in the therapy professions.

At the outset of an audit project an assessment should be made by someone with experience of what kind of expertise will be required throughout its course and then, if necessary, links made with appropriate personnel. It is surely unrealistic to expect people without relevant experience to design valid and reliable instruments; initially they need access to those with appropriate experience. Certainly the benefits of the help provided by audit facilitators was acknowledged by many of the participants in this study, and similar findings have emerged from studies of audit in other professions - for example, the study by Carroll et al of audit facilitators in general practice. ${ }^{17}$ Recognition is also required of the needs of these audit facilitators themselves, if they are to develop and sustain audit initiatives.

Concerns about motives for audit and confidentiality of findings are unlikely to be allayed, because as Packwood et al have argued, audit has moved increasingly from a private professional domain into the public interface between purchasers and providers. ${ }^{14}$ Moreover, organisational structures are unlikely to change in a way which mitigates the constraints which respondents thought that they imposed on their audit activities. The way forward is for these issues to be acknowledged in a forum which represents all those involved, and in which resolution can be sought by means of what Thomson and Barton refer to as mature and informed communication. ${ }^{8}$

Such a forum should be a unit based audit committee in which professionals, managers, and purchasers are represented with equal voice. Such committees existed in some of the fieldwork sites and the Department of Health has recommended that they be established in all trusts. ${ }^{18}$ The goal of the committee must be to develop clarity and unity of purpose about audit, as it is hard for staff to remain enthusiastic and committed when this is not the case. If this goal is not achieved, then the research reported here suggests that professionals may respond, albeit reluctantly, by steering the selection of audit towards what they regard as safe topics and away from those more complex aspects of care with a potential for unpredictable and possibly unwelcome results.

The committee should also develop an overall plan for audit activities and have the authority to mandate appropriate resources for audit. As Thomson and Barton argue, this would help to ensure that all the elements necessary for the successful completion of audit projects are in place. $^{8}$ Considering constraints attributed to inadequate resources and lack of expertise will of course have financial implications, albeit that these may be offset in due course by the increased likelihood of the successful completion of audit projects.

\section{Conclusion}

As Buxton has observed, audit is now seen by many as an inherently good thing; an activity that by definition deserves support and encouragement. ${ }^{19}$ The research reported here, however, indicated that audit in the professions of occupational therapy, physiotherapy, speech and language therapy, and clinical psychology was taking place in an environment in which various constraints had the potential to jeopardise progress. The extent to which commitment to audit is maintained in these and other professions may well depend on whether these constraints are resolved in the future.

This paper draws on a project funded by the Department of Health, and undertaken by a research team of which I was a member. The team directors were Maurice Kogan of the Centre for Evaluation of Public Policy and Practice, Brunel University and Sally Redfern of the Nursing Research Unit, King's College, London; other members were Anèmone Kober, Ian Norman, and Tim Packwood. The research was a collaborative effort by the team; this paper reflects those aspects of the analy- 
sis and writing for which I took particular responsibility. The views expressed in this publication are my own and not necessarily those of the Department of Health. Thanks are due to Jenny Lynden and Geraldine Reast for administrative and secretarial support.

1 Ellis R, Whittington D. Quality assurance in health care: a handbook. London: Edward Arnold, 1994.

2 National Nursing and Therapy Audit Networks. Leeds: Institute of Nursing, Leeds University, Newsletters, 1992-3.

3 Kober A, Redfern S. The four professions. In: Kogan M, Redfern S, Kober A, Norman I, Robinson S, Packwood T. Clinical audit in four health professions. London: Nursing Research Unit, King's College, 1994.

Research Unit, King's College, 1994.
4 Department of Health. Clinical audit in the nursing and therapy professions. London: DoH, 1994 .

5 Department of Health. Clinical audit: meeting and improsing tandards in healthcare. London: $\mathrm{DoH}, 1993$

6 Firth-Cozens J, Storer D. Registrars' and senior registrars' perceptions of their audit activities. Quality in Health Care 1992;1:161-4

7 Kerrison S, Packwood T, Buxton M. Medical audit: taking stock. London: King's Fund Centre, 1993. (Medical audit series No 6.)

8 Thomson R G, Barton A. Is audit running out of steam. Quality in Health Care 1994;3:225-9

9 Normand C, Ditch J, Dockwell J, Finlay A, Gaskell G, Henderson G, Whittington D. Clinical audit in professions allied to medicine and related therapy professions. Belfast: Health and Health Care Research Unit, Queen's University, 1991.

10 Ritchie J, Spencer L. Qualitative data analysis for applied policy research. In: Bryman A, Burgess B. Analysing qualitative data. London: Routledge, 1994

11 Kogan M, Redfern S, Kober A, Norman I, Robinson S, Packwood T. Clinical audit in four health profession London: Nursing Research Unit, King's College, 1994.

12 Black N, Thompson E. Obstacles to medical audit: British doctors speak. Soc Sci Med 1993;36:849-56.

13 Hearnshaw H, Baker K, Robertson N. Multidisciplinary audit in primary healthcare teams: facilitation by audit audit in primary healthcare teams: facilitation by

14 Packwood T, Kerrison S, Buxton M. The audit process and medical organisation. Quality in Health Care 1992;1:192-6.

15 Matchet A, Rose P. Medical audit in the quality process: practical implementation. International fournal of Health Care Quality Assurance 1992;5:15-7.

16 Firth-Cozens J. Audit in mental health services. Hove: Lawrence Erlbaum Associates, 1993:8.

17 Carroll L, Thirlwell M, Wilson A. Medical audit and the role of the facilitator. International fournal of Health Care Quality Assurance 1994;7:8-10

18 Mawhinney B, Nichol D. Purchasing for health: a framework for action. London: National Health Service Management Executive, Department of Health, 1993.

19 Buxton, M. Achievements of audit in the NHS. Quality in Health Care 1994;3(suppl):35-6.
8 